\title{
Center-Based Child Care and Differential Improvements in the Child Development Outcomes of Disadvantaged Children
}

\author{
Sarah Anne Reynolds ${ }^{1}$ (D)
}

Accepted: 10 June 2021 / Published online: 23 June 2021

(c) The Author(s) 2021

\begin{abstract}
Background Research finds center-based child care typically benefits children of low socio-economic status (SES) but few studies have examined if it also reduces inequalities in developmental disadvantage.

Objective I test if the length of time in center-based care between ages one and three years associates with child development scores at age three years, focusing on the impact for groups of children in the lower tercile of child development scores and in the lower SES tercile.

Method Using data from 1,606 children collected in a nationally representative Chilean survey, I apply a value-added approach to measure gains in child development scores between age one and three years that are associated with length of time in center-based child care.

Results Disadvantages at age one year were associated with lower child development scores at age three years. No benefits of additional time in center-based care were found for the non-disadvantaged group, but positive associations were found between more time in center-based care and child development outcomes for children with the SES disadvantage only. Center-based care was not associated with child development trajectories of children with lower child development scores at age one year, no matter their SES status.

Conclusions There is evidence that Chilean center-based child care reduces SES inequality in child development scores between ages one and three years, but only if children already were not low-scorers at age one year.
\end{abstract}

Keywords Center-based care $\cdot$ Early child development $\cdot$ Chile $\cdot$ Inequality

Sarah Anne Reynolds

sar48@berkeley.edu

1 School of Public Health, University of California, Berkeley 429 University Hall, Berkeley, CA 94720, USA 


\section{Introduction}

Research suggests that even very young children are on trajectories that result in inequality later in life (Doyle et al., 2009; Gertler et al., 2014). Low socio-economic status (SES) is one disadvantage that is associated with less satisfactory early child development outcomes. By age two years, statistically significant differences in IQ had emerged between British children of high and low-SES families, defined by a composite variable of parental education and occupation (Von Stumm \& Plomin, 2015). In the US, significant disparities in vocabulary and language processing efficiency were already evident at 18 months between infants from higher- and lower-SES families. By 24 months, there was a six-month development gap between SES groups (also defined by a composite variable of parental education and occupation) in processing skills critical to language (Fernald et al., 2013). A cross-country study of children from India, Indonesia, Peru and Senegal found that differences in child-development scores emerged by age nine months for children in the highest and lowest SES quintiles (defined by maternal educational and a wealth index) ranging between a quarter and a half of a standard deviation (Fernald et al., 2012).

Latin America is a region plagued with wealth inequality, which translates into child development disparities. Examining samples of young children from five Latin American countries, Schady et al. find differences in language skills between the highest and lowest wealth quintiles emerged by age three years (2015). In Ecuador and Colombia, the SES gradient in child development test scores widens with age among preschool children (Paxson \& Schady, 2007; Rubio-Codina et al., 2015). Data from Chile, where the current study is focused, also has significant wealth gaps in child development. Even though there are no differences in anthropometrics by SES as birth, differences in height-for-age z-scores emerge by 30 months suggesting that disadvantaged children have a weaker base of physical development supporting cognitive development (Behrman et al., 2017). Additionally, disparities in cognitive and socio-emotional skills emerge during the preschool years, although these decrease as children enter elementary school. Maternal education was the mediator that explained the SES gap in socio-emotional skills, but it explained less than half the wealth gap in cognition (Abufhele et al., 2020). These findings indicate that considering how early childhood interventions support low-SES children specifically is important for equity in Chile and the region.

An initial low level of child development is another disadvantage that has long term implications. Development is a cumulative process and subsequent development builds on the achievements of prior development (Cunha \& Heckman, 2007; Todd \& Wolpin, 2003). IQ at age two years is correlated with IQ at later ages, although the correlation weakens as the children age (Von Stumm \& Plomin, 2015). Using six longitudinal data sets, Duncan et al. confirm that cognitive measures prior to primary school (ages 5-6) predicted later academic performance (2007). Similarly, most children who start elementary school significantly behind their peers never close the readiness gap (Lee \& Burkam, 2002), and a lack of school readiness predicts many long-term negative outcomes (Zigler, 2006). Thus, children with initially low levels of child development - as found to be associated with low SES - may have difficulty catching up to their peers.

Children with both types of disadvantages-lower SES and lower child-development scores-remain with compounded disadvantages later in life. For example, literature on children with developmental disabilities suggests that those in low-SES situations have fewer resources for addressing these issues and thus may have worse adult outcomes than children with developmental disabilities in higher SES contexts (Evans et al., 2013). In 
Chile, parents' education level was positively associated with children's socio-emotional skills (as measured by the Bayley Scales of Infant Development) at 12 and 30 months of age. The cumulative nature of this association is revealed by the finding that 12 -month skills predicted 30-month socioemotional skills, though parental education was no longer a predictor once 12-month skills were included (Farkas et al., 2017); early disadvantage can persist and worsen. On the flip side, research has shown that cognitive ability can protect against SES disadvantages: scholastic achievement of youth ages 11 to 18 years old compensated for depressed mood associated with adverse childhood experiences (Gerard $\&$ Buehler, 2004). It is plausible that developmental ability could protect against SES disadvantage earlier in childhood.

Theory suggests that center-based childcare may be able to attenuate these disadvantages. The poverty literature has revealed the importance of the economic situation in shaping children's developmental outcomes, suggesting the pertinence of an ecological model of child development (Bronfenbrenner \& Morris, 1998). Children's processes are modeled to unfold in interaction and reaction to various environmental and contextual factors, from the mother's care to the broader societal contexts. This environmental focus also suggests that childcare also forms a significant part of the child's lived experiences, thus can also influence their developmental process. Center-based child care can attenuate the impacts of poverty if it provides stimulation and secure attachment that may be less available among impoverished households due to higher levels of stress.

The studies on the cumulative nature of development suggest the relevance of the sociocultural and psycho-social development models, as both of them generally consider child development to be sequential processes (Erikson, 1950; Vygotskiü, 1978). With respect to the sociocultural theory, a child care center may offer more appropriate challenges for the child within their zones of proximal development; the home may be more challenging for children to navigate with its organization oriented primarily to adults. Psycho-social development theory suggests that young children included in this study (ages 1-3 years) must develop autonomy before moving on to the subsequent stage (initiative, characterized by play); separation from parents is part of this process and center-based care may provide that safely.

Both theories correspond to the concept that more time in care will result in better child development outcomes. However, the ecological model, being environmentally focused, is more directly linked in that regard. The conceptualization of development as a sequential process suggests that appropriate developmental challenges must be available for more time to translate into development. So it is possible that development stagnates if the child care center either does not have challenges at the child's level or the child exhausts and masters all available challenges.

Literature is scant regarding if children with low child development scores benefit from center-based childcare, irrespective of SES. On the other hand, much research has shown that center-based care provides cognitive benefits and, less strongly, socio-emotional benefits for children from low-SES households (Anderson et al., 2003; Belsky et al., 2007; Berlinski et al., 2008; Camilli et al., 2010; Havnes \& Mogstad, 2011; Vandell et al., 2016), including in Chile (Centro de Estudios MINEDUC, 2013; Cortázar, 2015; Narea et al., 2020a, b; Reveco \& Mella, 1999). A smaller body of literature confirms these findings for children less than age 3 years (reviewed by Sylva et al., 2015; also Nores et al., 2019). However, most of the studies of children under age three years are evaluations of mainly small-scale, specific center-based care programs. Exceptions are studies that use national level data from Chile (Narea et al., 2020a, b), Germany (Kuehnle \& Oberfichtner, 2020) and the United Kingdom (Côté et al., 2013; Del Boca et al., 2018; Hansen \& Hawkes, 
2009) to show that center-based care can support cognition of very young children, particularly low-SES children.

Among observational studies, dosage analyses may better control for selection bias: instead of contrasting outcomes of children in center-based care to outcomes of children not in center-based care, these studies contrasted the outcomes of children in care for different lengths of time, more accurately modeling the exposure mechanism by which centerbased care may be effective. However, there are few of studies of this type. Notably, Belsky et al. (2007) found that vocabulary scores varied as a function of age of entry to care. Dosage effects were non-linear among low-income children: scores were higher if (low-SES) children entered child care before three months of age or after nine months of age and lower if they entered between three and nine months. No association between age at entry and vocabulary was found among children who were not poor. Zambrana et al. also found an increase in vocabulary with Norwegian children's increased time in care in high-quality care settings (2016). Children of mothers with lower levels of schooling in Quebec scored as well as children of mothers with higher levels of schooling on cognitive tests at age six and seven years only if the children of less-schooled mothers had more time in center-based child care between ages five months and four years (Geoffroy et al., 2010). On the other hand, studies from the US and Switzerland provide additional evidence has indicated that a higher time in center-based child care early in life can hinder child development as high time spent in care results in worse externalizing behavior (Averdijk et al., 2011; McCartney et al., 2010). Dosage analyses from Latin America, though limited, have findings generally consistent with the conclusion that center-based care supports child development in lowSES contexts, although, again, these studies focus on a specific programs (Behrman et al., 2004; Bernal \& Fernández, 2013; Noboa-Hidalgo \& Urzúa, 2012).

\section{The Chilean Context}

Chile comes in second to Costa Rica as the country with the highest income inequality among OECD nations. Unfortunately, this income inequality extends to inequality in child development outcomes as well. Children in low-income settings have few child development aids in the household, such as books, music, and toys designed to stimulate children; subsequently, those without such resources in the home score lower on child development tests (Behrman et al., 2010). A previous survey estimates $34 \%$ of children age three have some sort of developmental delay (Aguilera et al., 2006); language tends to be the area of delay that is the most common (Atalah et al., 2014). Interestingly, there is not a clear association between center-based care attendance and SES (Behrman et al., 2010).

Assessing the effectiveness of center-based care may be even more pertinent for Chile than the US and Europe, as an increasing number of Chilean mothers are entering the labor force. Chile is a high-income country, is a member of the OECD, and has similar rates of participation in center-based care for children less than age three years (around 30\%) as countries in the European Union and the US (Janta, 2014; Ministerio de Desarrollo Social, 2019). Unlike these countries, however, Chile's female to male labor force participation ratio is relatively low at 68 (e.g. 82 in the US and Spain, 84 in France and Australia) (The World Bank, 2017) and around $45 \%$ of Chilean children under age three years have employed mothers (Ministerio de Desarrollo Social, 2019) in contrast to around $60 \%$ of children in the European Union and the US (OECD - Social Policy Division, 2016; United States Department of Labor, 2016). However, between 2005 and 2015 the female labor 
force participation rate increased ten percentage points in Chile (The World Bank, 2017); if this upward trend increases, many more young children may be enrolled center-based care.

Chile recently experienced a rapid expansion of early childhood programs for children less than four years of age to serve working mothers. The largest change occurred in 2013, when Chile expanded the supply of child care vouchers for low-income families from children as young as four years to children as young as two years. (See Reyes \& Urzua, 2012 for more detail on the expansion.) This paper does not directly evaluate the expansion, but does speak to how center-based care has supported early childhood development among those who are enrolled in child care. Quality was not initially guaranteed. A governmental quality analysis from 2012 indicates $35 \%$ of public child care institutions evaluated were of low or insufficient quality (Zafe Contreras (Ed.), 2013). The evaluations included curriculum, treatment of children, hygiene and feeding, infrastructure and safety, financial viability, and management. Perhaps because of these low-scoring establishments, a 2015 law (Ley $\mathrm{N}^{\circ} 20.832$ ) required day care and preschools to comply with minimum standards for trained personnel, physical space and sanitary requirements, and curriculum. However, this analysis uses data prior, so quality varies greatly for the children in this sample, though parents' perception of their children's center-based care establishments is very high, with little variation.

\section{Contributions \& Research Questions}

The primary contribution of this study is to determine if center-based child care influences inequality along two dimensions (poverty and child development) instead of one dimension (typically poverty). This innovation considers both theoretical frameworks of environmental disadvantage and the disadvantage of being earlier in the developmental process, should child development be sequential in nature. The literature has little emphasis on how centerbased care may help children who are not low SES but still score poorly in child development. This may be because those with low SES and low child development scores are overlapping groups. However, there still remains heterogeneity: school-readiness gaps between low-SES and higher-SES children do not perfectly align with the SES measures (Waldfogel \& Washbrook, 2011). Exploring the effects of center-based care on children who are not SES-disadvantaged but with low child development scores can provide insight into mechanisms. For example, if center-based care helps children of low development scores, as in the case of Head Start, it is likely that a compensatory educational model is at work (Bitler et al., 2014). (In a compensatory model, education supports those at the bottom of the distribution, in contrast to the model of skill-begets-skill, which benefits those at top of the distribution.) On the other hand, in the case where center-based care only improves scores of low-SES children, this improvement could stem from an environmental, rather than educational, aspect of center-based care (Berry et al., 2016).

A secondary contribution is to examine the impact of center-based care on children one to three years of age using a dosage approach; these children are typically underrepresented in most center-based care studies and, as a result, we know little about the effects of centerbased care for this particular age-group. Child care may not have the same impact on younger children as older children who are experiencing different stages of development.

My analysis complements the Noboa-Hidalgo and Urzua Chilean study on low-SES children in public preschool (2012). They find children in care for seven months do better than children in care for five and six months, suggesting as much as a 0.25 standard deviation increase in feeling expression for an additional month in center-based care. The range 
included in the current study is much larger, 0 to 34 months. This is also a broader time span analyzed than the additional four months of universal preschool some German threeyear-olds received resulting from a legislative timing change (Kuehnle \& Oberfichtner, 2020). Examining a longer exposure period can reveal if these findings based on a short duration are consistent for a broader range of time enrolled.

The current study also has some similarities to other studies using the ELPI data set. Narea, Arriagada and Allel examine the impact of center-based care on young children (Narea et al., 2020a, b). Their study confirms that low-SES children benefit from care, but does not explore the impact on children who have lower child development scores at baseline. Additionally, their study examines the bivariate variable "in care between 24 and 36 months", and does not examine length of time in care. A similar study contrasts the impact of different types of non-maternal care (center-based, grandparent, other relative, and non-relative) between ages 6-12 months on a variety of developmental outcomes at ages 24-48 months and also finds center based care to be beneficial although not for low-income children (Narea et al., 2020a, b). The current study further contributes to this examination of inequality in child development outcomes resulting from center-based care for low-SES children by considering length of time in care between ages one and three years, allowing for a broader window than the six- to twelve-month focal period of Narea et al.'s study $(2020 \mathrm{a}, \mathrm{b})$. Additionally, the approach of the current study allows for a study of change in development, while Narea et al.'s design on the attendance of children at the youngest ages does not allow for this type of analysis.

The data provide a number of analytical advantages. The majority of studies on this younger age-group use data from small or medium-sized trials which are not representative of the full population, exceptions being those mentioned from Chile, Germany, and the UK. In contrast, the sample in the current study is quite large-over 1500 children. Additionally, I include children from the general population, not just low-SES children, which allows for insight regarding the growth of inequality in child development and how centerbased care may address this. I employ a dosage analysis, which removes some concerns for selection bias into care, as discussed in the literature review. Furthermore, the longitudinal data and a very rich set of controls (including parental sociodemographic characteristics, mother quantitative and language abilities, the learning environment at home, other measures of parental investments and baseline outcomes) help alleviate endogeneity concerns.

Given the multiple theories suggesting different types of disadvantage may result in lower levels of child development, I first hypothesize that disadvantages at age one year (low SES, low child development scores, and both) are associated with inequalities in child development outcomes at age three years, with even lower scores for children experiencing both disadvantages. Given the mechanism of more time in a safe environment with more opportunities to practice skills in a setting designed to be at the child's skill level, I test a second hypothesis that a longer duration in center-based child care in early childhood can help reduce inequalities in child development outcomes by age three years. I compared more advantaged children to three groups of children who had risk factors at age one year for lower-scoring child development at age three years: children from low-SES families (but not with low child development scores), children with low child development scores at age one year (but not from low-SES families), and children both from low-SES families and with low child development scores. In addition to hypothesizing that a longer number of months in care will reduce inequality, I also hypothesize that a longer daytime exposure to center-based child care would reduce inequality. To test this third hypothesis, I divide the sample between children who attended half days and those who attended full days to explore if a longer number of hours at the center may have been more beneficial for some 
groups. In particular, if longer hours allow for more stimulation, more hours each day in center-based care could benefit children with lower child development scores. Finally, to consider the fourth hypothesis that children are in different developmental stages at different ages and thus would experience the effects of childcare differently, I contrasted these results for children who entered prior to age two years and for children who entered after age two years to test for differential influences by age at start. ${ }^{1}$

\section{Materials and Methods}

\section{Design and Procedure}

The data used for this study come from the Encuesta Longitudinal de Primera Infancia (ELPI-Chilean Early Childhood Longitudinal Survey). The 2010 survey is a nationally representative database of 15,175 children born between 1st January 2006 and 31st August 2009. The mother of the household was chosen to respond to the questionnaire; if the mother did not live with her child, an alternate household member responded in her place (less than $2 \%$ of cases). Children were evaluated with developmental tests on a separate visit by a psychologist. The mothers and children were re-surveyed and re-evaluated in 2012, with a $15 \%$ attrition rate. These data are de-identified and publicly available, so IRB approval was not required for this secondary data analysis. There are no conflicts of interest to declare.

\section{Participants}

I focus this study on children three years (36-47 months) in 2012, who were approximately age one year when surveyed in 2010 (8-23 months). I restrict the sample to children who received center-based child care at some point between the 2010 and 2012 survey rounds. Children could have enrolled earlier than the 2010 round, but since this study takes a value-added approach, I only consider months in center-based care between the two survey rounds.

2182 of the 3326 children $36-47$ months of age in the 2012 survey had attended centerbased care between the 2010 and 2012 survey rounds. I restrict the sample to the population of children who have participated in center-based care because I find plausible evidence of selection-bias into enrollment. Though I considered including the non-attending children in order to improve the precision of the model, the attending and non-attending children had at least moderately significant differences between regression coefficients associating the control variables and the child development scores for three of the tests (TADI socioemotional $p$-value $=0.006$, TADI cognitive $p$-value $=0.11$, TVIP $p$-value $=0.168$ ). Instead of including all three-year-olds, as a robustness check I include a specification with inverse probability weights combined with sample weights to modify the estimates in order to generate nationally representative estimates. In contrast to the children age three who had not been in center-based care between 2010 and 2012, children who received center-based

\footnotetext{
1 Age at enrollment and length of time are confounded in child-care studies since a longer time in care implies an earlier enrollment. Since not all children are surveyed at the exact same age, considering age at start was more meaningful for policy than length of time in care.
} 
care lived in households with more income and wealth, lived with mothers who are more schooled and score higher on the math and verbal skills test, and had higher baseline child development scores in addition to lower scores on the toys and activities indices.

I excluded some observations that were missing essential information for the analysis. 193 of the children were tested well after they were surveyed about child care, so they are missing information on child care during this gap. Seven children were missing information on duration of their child-care attendance. In addition, some children had not been evaluated in the child development tests that I used as outcome variables or baseline controls $(\mathrm{N}=214)$.

162 children had a gap in child care, meaning that their months in care were not continuous. I dropped these observations because they do not align with the standard trajectories that would provide insight for policy. However, I do include them in a robustness check.

The final sample size was 1606 children, $81 \%$ of the three-year-old children for whom I could confirm had attended child care continuously between 2010 and 2012.

\section{Measures}

Time in center-based child care This variable was defined as number of months in centerbased care between 2010 and 2012. Information on center-based care was collected via retrospective histories. The caregiver was surveyed regarding multiple periods of the child's life, up to the current age (0-3 months, 3-6 months, 6-12 months, 12-18 months, 18-24 months, 2-3 years, 3-4 years). For each of these periods, the caregiver responded if the child had been enrolled in center-based child care and for how many months and weeks. Thus, the number of months in care could be partial. I only used the period between the 2010 and 2012 survey waves as the variable of interest; participation in center-based care prior to the 2010 survey round was used as a control variable. The children typically spent at most 10 months per year in center-based child care, probably due to Chile's generous vacations.

Child development measures All children were tested by child development psychologists in a home visit after the survey data collection. I chose the 2012 outcomes in the broad child development arenas in which the ELPI provides tests: cognition, language, and socio-emotional. These three areas are all included in the Test of Infant Learning \& Development (TADI), a Chilean assessment administered directly to children ages three months to six years (Pardo et al., 2012). (Though the TADI also includes a test of motor skills, the outcomes in this arena do not correlate as well with age so I do not use this outcome.) The TADI begins with easy tasks for the age level. Progressively harder ones are given, which allows for the child to be evaluated over the range to their maximum achievement level, stopping when the failure criteria are met. Though developed in Chile, the items were evaluated by an expert jury in development psychology and infant evaluation. High standards for internal consistency were maintained (with the Cronbach alpha 0.9 in all dimensions). The TADI was tested for cultural validity in rural and indigenous regions and items that indicated cultural bias were eliminated (Pardo et al., 2012). The psychometric study was done by testing children of low-, medium-, and high-educated mothers in different age groups with 23-40 children in each cell; developmental and SES gradients were confirmed in each child development realm.

The test that is best aligned with the cognitive domain on the TADI is the Battelle Developmental Inventory 2nd Edition, Screening Test (Battelle) (Newborg et al., 1996). The test was developed based upon the theory that children achieve specific developmental 
milestones in sequence and that reaching milestones generally depends on mastering preceding milestones. Items cover five domains: Adaptive, Personal/Social, Communication, Motor, and Cognitive. The screening version is not powered to identify subscales; the 100 questions most correlated with the total score from the 400 question non-screening version were chosen to comprise the screening test. The cognitive and language domains are most related to diagnostic findings (Glascoe \& Byrne, 1993), and, using the ELPI data on threeyear-olds, the Battelle screening tests correlates slightly higher with the TADI cognitive $(\mathrm{r}=0.62)$ than the TADI language $(\mathrm{r}=0.59)$. Thus, I categorized the Battelle as a cognitive test.

The Peabody Picture Vocabulary Test (PPVT) assesses language development and has been translated to Spanish and has been validated in Mexico and Puerto Rico (Dunn \& Dunn, 1997). The adaptors of the test used item analyses to determine which words to include on the Spanish PPVT; items may differ from those on the English version. The PPVT has been widely used throughout Latin America, and appears to be effective in detecting the impact of various interventions on language development (Crookston et al., 2011). Some target words were adapted to the Chilean context, i.e., a more commonly used word was substituted for the target word if the original was not well known in Chile.

Measuring socio-emotional well-being, the Child Behavioral Checklist (CBCL) is a well-validated, reliable, parent-completed checklist consisting of 99 items assessing a range of problem behaviors (Achenbach \& Rescorla, 2000). The checklist has two major scales: Externalizing and Internalizing behaviors. The Externalizing scale is comprised of two subscales (Aggressive Behavior and Attention Problems), while the Internalizing scale includes four subscales (Emotionally Reactive, Anxious/Depressed, Somatic Symptoms and Withdrawn). I used the overall composite score and reverse code so that a higher score is more positive, as with the other tests.

For each test, I used the entire set of children tested (not just those who had been enrolled in child care) to standardize scores non-parametrically by dividing the sample into two-month age windows. Each grouping of children have their test scores standardized to a mean of 0 and a standard deviation of 1, as has been done before (Fernald et al., 2011). Scores were capped at 4 standard deviations; at most 9 observations of any one test were capped. A higher score is indicative of a more positive outcome.

As required in a value-added model, I controlled for child development at baseline. In 2010, the children were tested with the full Battelle Developmental Inventory 2nd Edition (not the screening edition as in 2012), so there were a sufficient number of questions administered such that subscales were provided in the data (Newborg et al., 1996). I used the 2010 age-standardized scores from the Battelle inventory in the three subareas most closely related to the outcome variables: cognitive, language, and personal-social (closest to socio-emotional). Prior to ELPI, the Battelle Inventory had been used in Chile for three large evaluation projects: the governmental integrated child development program Chile Crece Contigo (Chile grows with you), a governmental preschool evaluation program, and the UNICEF sponsored program Juguemos con nuestros hijos (We play with our children). The administration of the test was done in accordance with the Spanish version, Inventario de Desarrollo Battelle (De la Cruz \& Gonzalez, 1998). Previous research from Chile's Centro de Estudios de Desarrollo y Estimulación Psicosocial (Center for Development and Pscyho-Social Stimulation Studies-CEDEP) reports good psychometric properties of the test for a Chilean sample of almost 1500 children (Cronbach's alpha between 0.71 and 0.94) (Seguel et al., 2012).

Disadvantage I divided the sample along two distinct axes of disadvantage. I used participation in a government conditional cash transfer Subsidio Unicio Familiar 
(SUF-Unique Family Subsidy) as indication of SES disadvantage. Eligibility for this subsidy is based on "an instrument that aims at assessing the household income generating capacity and its vulnerability to shocks" (Amior et al., 2012). It includes income measures, education measures, and household needs based on size and composition. To enroll, social workers visited applying families and filled out a form assessing income, assets, and social inclusion, from which eligibility was calculated. The formula is not available to prevent households from gaming the system. All who reached the threshold of the proxy means tests received the transfer although parents with formal employment were not eligible. The families received the subsidy for three years, after which they could re-apply. The program is considered to have relatively good take-up and coverage because social workers facilitate the enrollment process (Amior et al., 2012). In the analytical sample 32\% of children live in families receiving SUF. I used SUF as the determinant of SES disadvantage because of its policy relevance: should additional policy emerge around center-based care specifically targeting low-SES children, the children can be easily accessed through administrative infrastructure.

I established the child developmental disadvantage using baseline (2010) Battelle total score (age-standardized). To parallel the magnitude of disadvantage established by SUF as well as that previously documented in the literature (Aguilera et al., 2006), I considered children in the lowest tercile to be vulnerable in the child development realm. The typical BDI cut-offs for developmental delays are not used due to concerns with cultural biases. The technique of contrasting the sample by quantiles is frequently used in studies for assessing wealth gradients in child development (Fernald et al., 2011, 2012; Paxson \& Schady, 2007; Rubio-Codina et al., 2015). In a robustness check I consider children in the lowest sixth of the distribution to be developmentally disadvantaged.

Additional covariates I controlled for child sex. The outcome variables are age standardized, so I did not control for child age. (When including age and age squared in the main regressions, their coefficients were insignificant.)

I controlled for additional factors that influence child stimulation. The survey inquires if the children were in the center a full day or a half day. $47 \%$ of children always attended full days and $49 \%$ always attended half days. I use a dummy variable for full day or half day as a control variable. Only 71 children had a mixed history of full day and half day child care. I assign the full-day dummy variable a value of 1 for the 46 children who had attended the center for a full day for more or equal months than they attended for a half day. I also include having been in center-based child care before 2010 as a control variable. I additionally control for the log of the number of months between 2010 and 2012 that the child has been in grandparent or informal care (neighbor or other relative) since these care types have been shown to influence child development in Chile (Narea et al., 2020a, b). These alternative care-types could occur simultaneously in the same developmental period as center-based care. Other variables in the child stimulation category come from the 2010 HOME scores (Home Observation of the Environment). A factor analysis of the questions resulted in two factors, one that represents a toy index, and another that represents stimulating parental activity. (See Supplementary Table A1 for questions and factor loadings.)

I controlled for mothers' verbal and math ability and education as measured by standardized scores from the Wechsler Adult Intelligence Scales (WAIS). I defined mothers' education as a categorical variable with the base level as tertiary (completed technical school or university), and the other two categories being completed secondary and less than completed secondary.

I included variables for number of siblings, and dummy variables for if a grandparent and father were present in the household. I controlled for log monthly household income 
and generated two asset indices (appliances and electronics) using principal-component analysis separately for each category of assets. (See Supplementary Table A1 for components \& factor loadings.) I included an urban-rural dummy, and I also controlled for the month the 2012 survey was administered, since there is a negative association between scores and being tested later in the year. This time trend may be due to difficulty in following-up, perhaps due to the child having moved or family situation that makes it difficult to schedule the interview, which may result in stress and thus lower scores.

A few observations had missing values of the control variables for which I imputed the mean or modal value ( $\mathrm{N}=14$ for the toy index, $\mathrm{N}=3$ for maternal education, and $\mathrm{N}=2$ for household income).

\section{Statistical Analyses}

To determine if the disadvantages identified in the 2010 survey round corresponded to lower 2012 child development scores, I compared the 2012 child development scores of children within different categories of disadvantages (child-development disadvantage, SES disadvantage, both disadvantages) to scores of children without disadvantages.

I then estimated the association between months in child care between 2010 and 2012 and child development measures by applying ordinary least squares regression in a valueadded framework. ${ }^{2}$ This approach, while not causal, takes into account a good portion of the unobserved differences between groups by controlling for the baseline child development scores in addition to the rich data about the child's family and environment available in the ELPI data. I estimate

$$
\mathrm{Y}_{2012}^{\mathrm{j}}=\mathrm{a}_{0}+\mathrm{a}_{1} \mathrm{~T}+\mathrm{a}_{2} \mathrm{~V}_{2010}+\mathrm{a}_{3} \mathrm{~T} * \mathrm{~V}_{2010}+\mathrm{a}_{4} \mathrm{Y}_{2010}+\mathrm{a}_{5} \mathrm{C}+\mathrm{a}_{6} \mathrm{X}_{2010}+\mathrm{e}
$$

$\mathrm{Y}_{\mathrm{j}}$ is the $\mathrm{jth}$ outcome variable (cognition, language, or socio-emotional on the TADI; or Battelle, PPVT or CBCL) in 2012. T is log months in child care between 2010 and 2012. I controlled for 2010 Battelle child development scores $\left(\mathrm{Y}_{2010}\right)$. $\mathrm{V}$ is a vector of disadvantage classifications, with the omitted category being no disadvantage. $\mathrm{C}$ is child care characteristics: the full-day dummy and if the child had been in child care prior to 2010 survey collection. $\mathrm{X}_{2010}$ are child, mother, and household characteristics. The error term is represented by e and I use robust (Huber-White) standard errors.

I am interested in coefficients $a_{1}$, which will indicate if there is an overall association between of length of time in center-based care and tests of child development, and $\mathrm{a}_{3}$, which indicates if the associations differ by disadvantage type. The main source of bias and thus concern that conclusions are non-causal is likely to be omitted-variable bias if the time at which the children entered child care is correlated with non-observables. However, because I only study children who have ever been in child care, I believe this bias to be smaller than the omitted-variable bias in studies that compare children in center-based care

${ }^{2}$ The lagged dependent variable model is a variant of a change model. Equation (1) is equivalent to.

$$
\mathrm{Y}_{2012}^{\mathrm{j}}-\mathrm{a}_{4} \mathrm{Y}_{2010}=\mathrm{a}_{0}+\mathrm{a}_{1} \mathrm{~T}+\mathrm{a}_{2} \mathrm{~V}_{2010}+\mathrm{a}_{3} \mathrm{~T} * \mathrm{~V}_{2010}+\mathrm{a}_{5} \mathrm{C}+\mathrm{a}_{6} \mathrm{X}_{2010}+\mathrm{e},
$$

which is equivalent to the following if $\mathrm{a} 4=1$ :

$$
\Delta \mathrm{Y}=\mathrm{a}_{0}+\mathrm{a}_{1} \mathrm{~T}+\mathrm{a}_{2} \mathrm{~V}_{2010}+\mathrm{a}_{3} \mathrm{~T} * \mathrm{~V}_{2010}+\mathrm{a}_{5} \mathrm{C}+\mathrm{a}_{6} \mathrm{X}_{2010}+\mathrm{e}
$$

However, allowing $\mathrm{a}_{4}$ to vary based on the child development realm allows the relationships to be more flexible, so I find the value-added, lagged dependent variable model preferable to the change model. 
to children not in center-based care, as discussed in the section on sample size and restrictions. Additionally, the children who had gaps in care were not included in the analysis, so care is relatively continuous since time of enrollment; the sample should not be biased by circumstances related to exit from child care. The bias introduced by differential time spent in child care is controlled for by a dummy variable for full-time (in contrast to part-time) enrollment and is also considered in a heterogeneity analysis.

I contrast children who participated in half-day care with children who participated in full-day care, as described earlier in the section on "additional covariates." The circumstances of families who are able to provide home or relative care for their children for half the day are different than those who enroll their children in full day care. It is of note that the average time spent in care for those in full day is 6 months longer than those in half day, suggesting those in full day care enter earlier, perhaps due to fewer options in home care. In a second heterogeneity analysis, I contrast children who entered very early (prior to age 2 years) with those who entered when older (age 2 or later); these children's families also may have faced different circumstances around how long parents or relatives could care for the child at home.

I compared models that were linear, log, and quadratic in months in center-based care. They differed little in model fit, so I presented the log specification, which suggests additional months in center-based care have diminishing marginal returns, as has been found elsewhere in the literature on Chilean center-based cares (Noboa-Hidalgo \& Urzúa, 2012).

Because the models fail multiple hypothesis testing both using Bonferroni corrections and the Westfall and Young step-down resampling method that applies a family-wise error rate, I include estimates of an index of the outcome variables, generated by exploratory factor analysis which indicated a single factor. This variable summarizes all outcomes, thus associations found with this variable I consider to be the most robust. This index is not intended to be a substitute for the main findings, but rather confirmation that the findings are not spurious. An alternate composite score, created by averaging the six standardized test scores, yielded very similar results to the factored composite score, confirming the robustness of the construction of the composite score. The correlation coefficients of the composite score variable with the individual tests confirm their similarities $(\mathrm{r}$ is around 0.8 with the TADI tests and Battelle, with PPVT $r=0.69$, with CBCL $r=0.33$ ). Because the CBCL has the least weight in the index and the CBCL test is least correlated with the other outcomes (perhaps because it is parent-response rather than psychologist administered) the reader may wish to consider the $\mathrm{CBCL}$ as a unique outcome in addition to the composite index.

Additional robustness checks include a specification with observations of children whose center-based care attendance was not continuous, a specification that applies inverse probability and survey weights, and a specification that uses a more restrictive cut-off for child development vulnerability. All analyses were done using Stata 14.

\section{Results}

\section{Descriptives}

Among the analytical sample, $21 \%$ and $20 \%$ have the child-development disadvantage (only) and the SES disadvantage (only) respectively, and $11 \%$ of children have both disadvantages, which is expected if the disadvantages were independent. This is unexpected, 
however, due to the large literature suggesting that SES predicts low child development scores.

Summary statistics (Table 1) confirmed that children with the SES disadvantage (recipients of the SUF social welfare transfer) have lower values for the income, appliances, and electronics variables. Their mothers score worse on mathematic and verbal skills tests and have lower levels of education. Recipients of SUF are less likely to live with fathers and more likely to live with grandparents. Children with both developmental and SES disadvantages generally have more disadvantage in these specific SES variables than children with only the SES disadvantage. Children with only the developmental disadvantage are more likely to be male and do fewer activities with parents than children without disadvantages.

The distribution of months in center-based child care is similar across the disadvantaged populations (Fig. 1). 34 months is the maximum number of months in child care between rounds; the time between surveys was approximately two years and a child may have been tested early in 2010 and late in 2012. The average number of months in care was 11.7. In the regressions the coefficient on the time-in-care variable can be interpreted as the change associated with a $100 \%$ change in time in care. Since the average time in care was around one year, I can roughly conclude that the size of the change in outcome variables is what is estimated to result from an increase from one year to two years in care. Similar to the results for selection into the sample, children with longer time in care lived in households higher in SES, but the differences between the upper tercile and lower tercile of time in care are generally not as great as when contrasting children in-sample to children out-of-sample.

\section{Hypothesis 1 Result: Disadvantages at Age One Year Predict Inequalities in Child Development Outcomes at Age Three Years I found that disadvantages in} 2010 correspond to lower scores in 2012 child development tests (Fig. 2, Supplementary Table A2). Children with any disadvantage perform $0.165-0.497$ of a standard deviation worse than children without disadvantages; most differences are statistically significant (Supplementary Table A2). Though the mean scores for the distinct disadvantage groups are not statistically different, scores of children with only the SES disadvantage are on average 0.04 standard deviations higher than scores of children with only the child-development disadvantage. Children with both disadvantages score even worse than children with a single disadvantage; differences in mean scores from those with both disadvantages average 0.04 standard deviations (child-development disadvantage) and 0.07 standard deviations (SES disadvantage). The disadvantages, however, are not additive, in that the size of the disadvantage from both disadvantages is substantially less than the sum of the sizes of the disadvantage from each separately. Because the confidence intervals of the mean scores among the disadvantaged groups overlap for all domains (Fig. 2), I cannot reject that having both disadvantages is any worse than having one disadvantage.

When controlling for child development scores at age one year and additional covariates, the mean scores at age three are 0.2-0.4 standard deviations lower for the children with a child-development disadvantage than for children without disadvantages. This increase in inequality, however, is only statistically significant for the PPVT (Table A3, Disadvantage Indicators). For children with SES disadvantages, the differences are larger, ranging from -0.3 to -0.7 of a standard deviation, with most of the coefficients (measures of increase in inequality) being significant at $1 \%$. The increase in inequality 


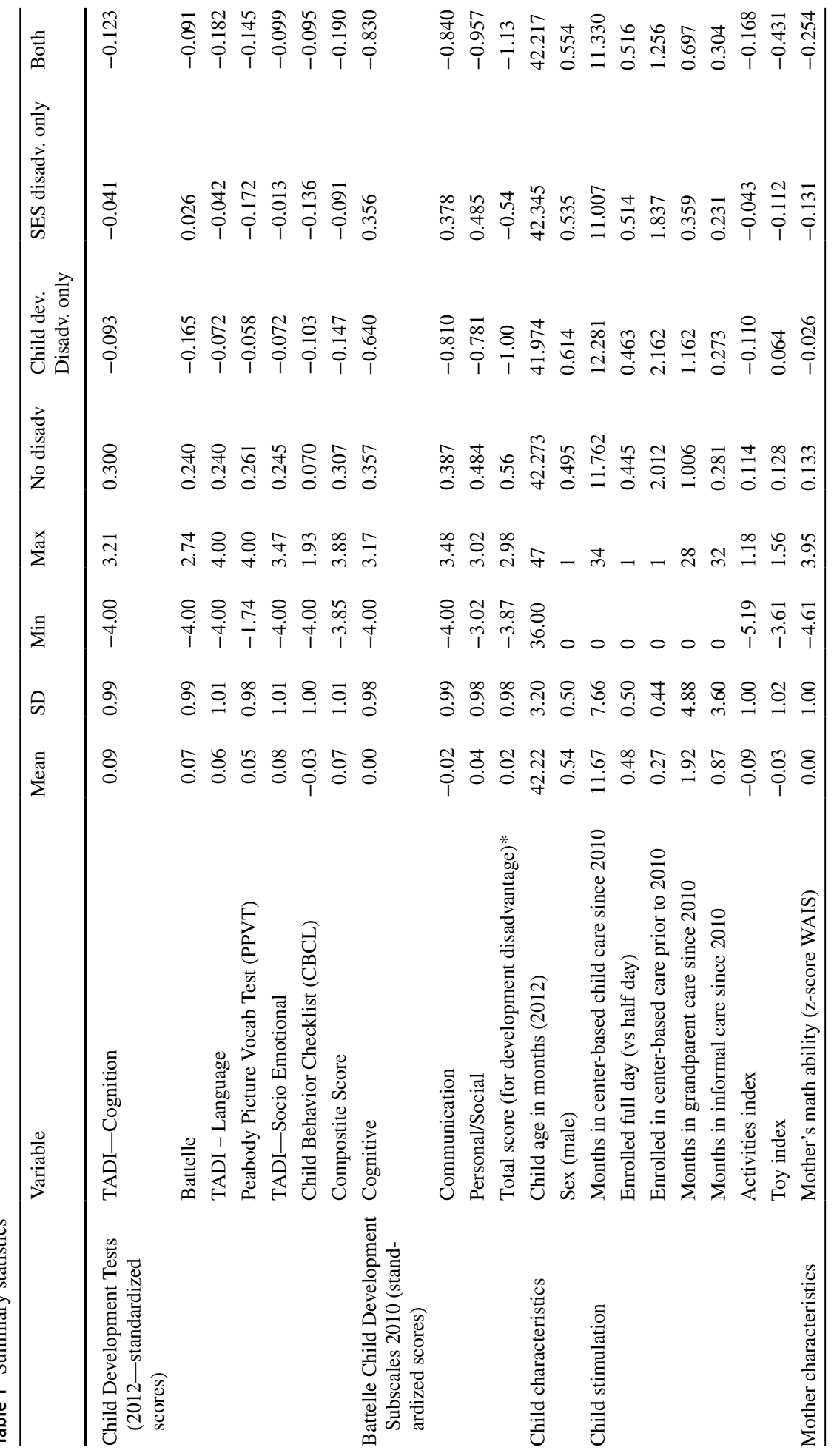




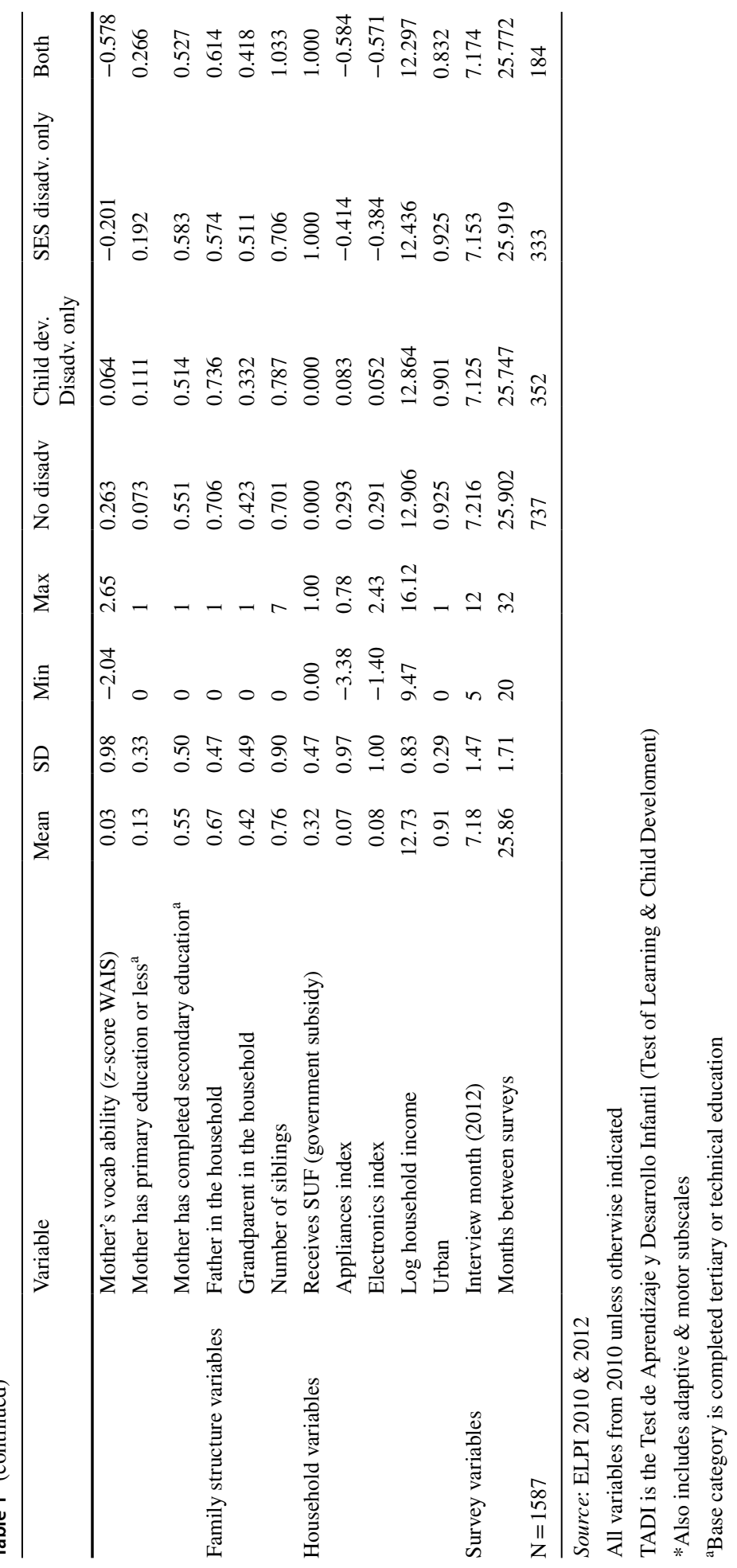




\section{Months in Center-Based Care}

Distribution by Disadvantage
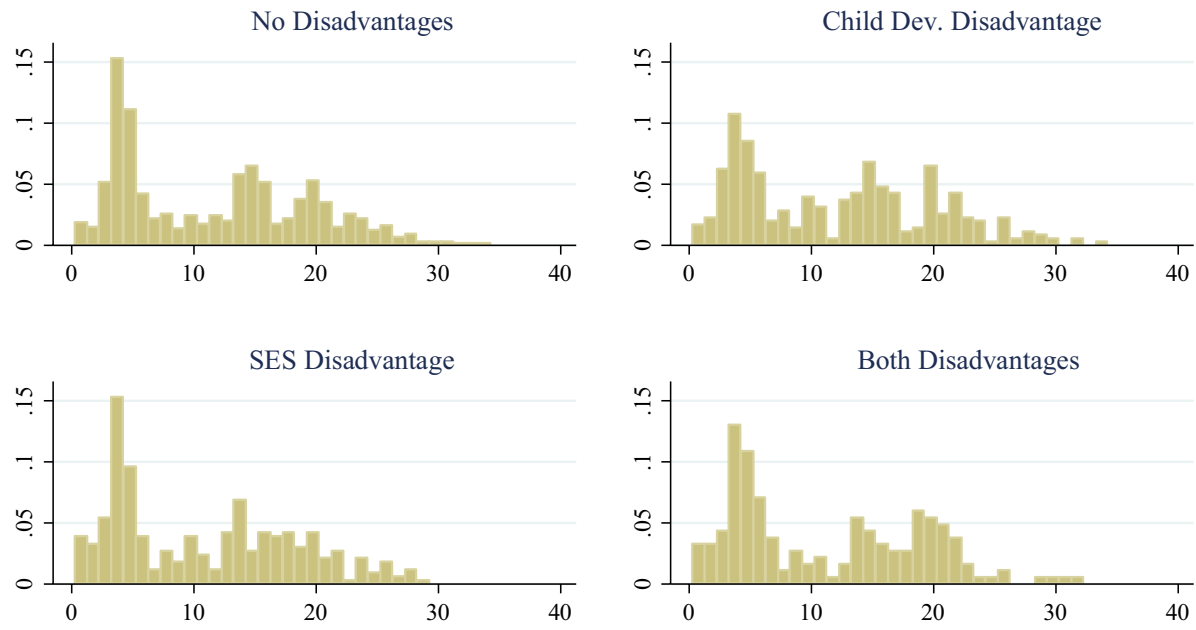

Fig. 1 Months in center-based care-distribution by disadvantage

for those with both disadvantages (in contrast to those with no disadvantages) falls in the middle of magnitudes of the differences of those with a single disadvantage. This may be because those with an SES disadvantage but not a child-development disadvantage have "farther to fall," since their scores were initially higher.

\section{Hypothesis 2 Result: Center-Based Child Care Reduces but Does not Close The Inequality Gap for Children with the Ses Disadvantage; No Significant Impact on the Inequality Gap for Children With Child-Development Disadvan-}

tages Among the population with no disadvantages, length of time in center-based child care (adjusted on a log scale) is not associated with child development outcomes, even when controlling for a variety of covariates (Fig. 3 \& Supplementary Table A3). However, among children with only the SES disadvantage there are some gains in child development scores: a 100\% increase in length of care (representing an increase from one to two years on average) is associated with a 0.16 increase $(p<0.05)$ in the cognitive TADI score, a 0.11 increase $(p<0.1)$ in the socio-emotional TADI score, and a 0.11 increase $(p<0.1)$ in language scores on the TADI and the PPVT. Although the coefficients on the language scores are only marginally significant, the similar magnitudes indicate the robustness of this finding. Furthermore, an $100 \%$ increase in center-based child care was associated with an increase of $0.14(p<0.05)$ in the composite child development outcome. These positive gains from more time in care, however, are smaller than half the gap in scores between the non-vulnerable children and the SES vulnerable children.

For the children with the child-development disadvantages only, there were fewer (though still positive) associions found. A doubling of time in center-based care was associated with a 0.14 reduction in socio-emotional score on the CBCL $(p<0.1)$ and a smaller reduction on the cognitive TADI (not statistically significant). The other test 
Mean Standardized Scores, 2012

By 2010 Vulnerability Type
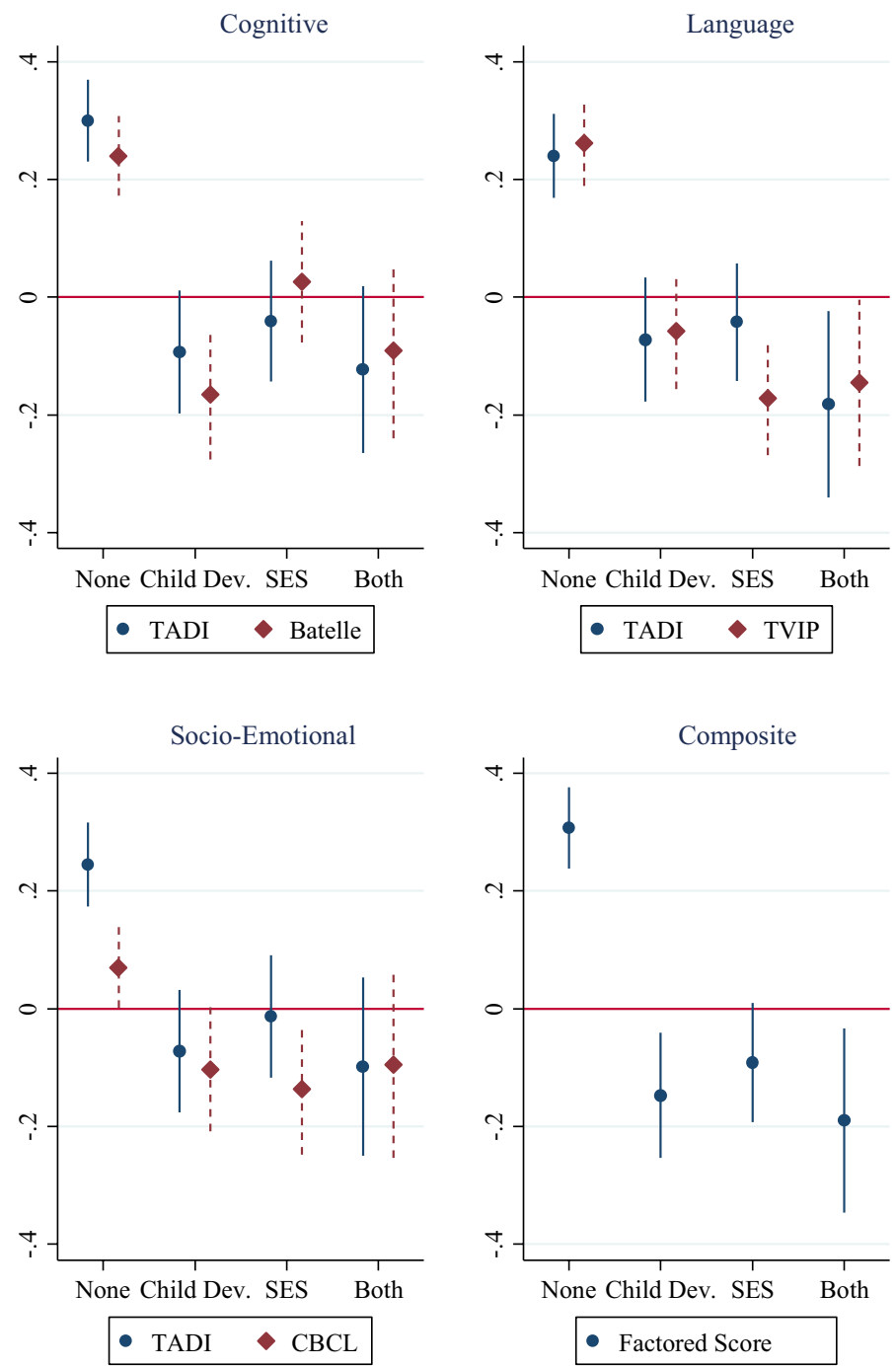

Fig. 2 Mean standardized scores, 2012, by 2010 vulnerability type

scores also increased, but, with the exception of the PPVT scores, magnitudes were much lower and these increases were not statistically significant.

For children with both disadvantages, most changes in child development scores attributed to center-based child care were small and statistically insignificant. The TADI language and socio-emotional tests had coefficient estimates with increases of similar magnitudes as those associated with center participation among the population with the child-development disadvantage. These coefficients, however, were not statistically 
Improvement in Standardized Scores

By 2010 Vulnerability Type:

Coefficient on Natural Log of Months in Center-Based Care
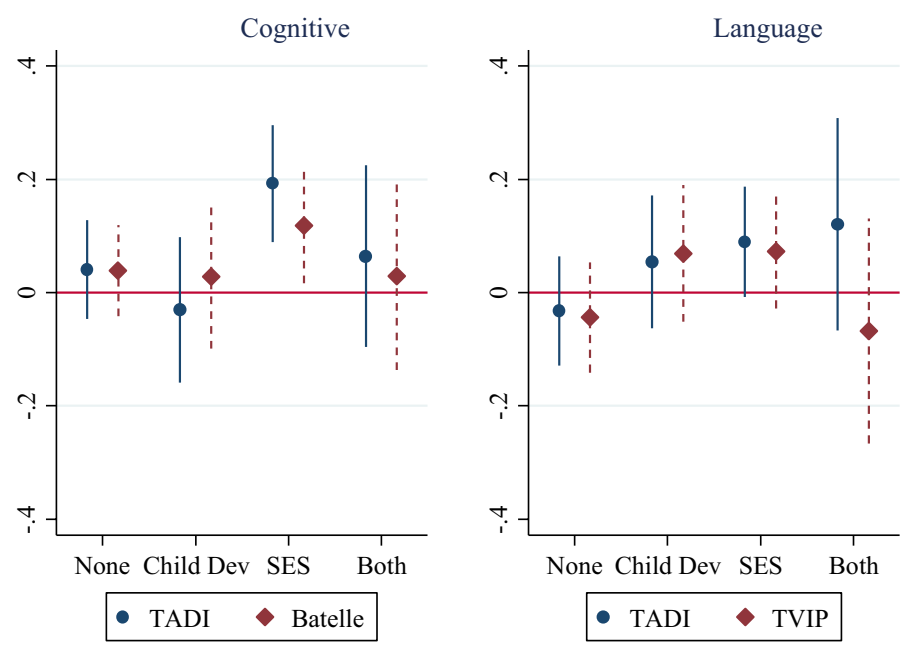

Socio-Emotional
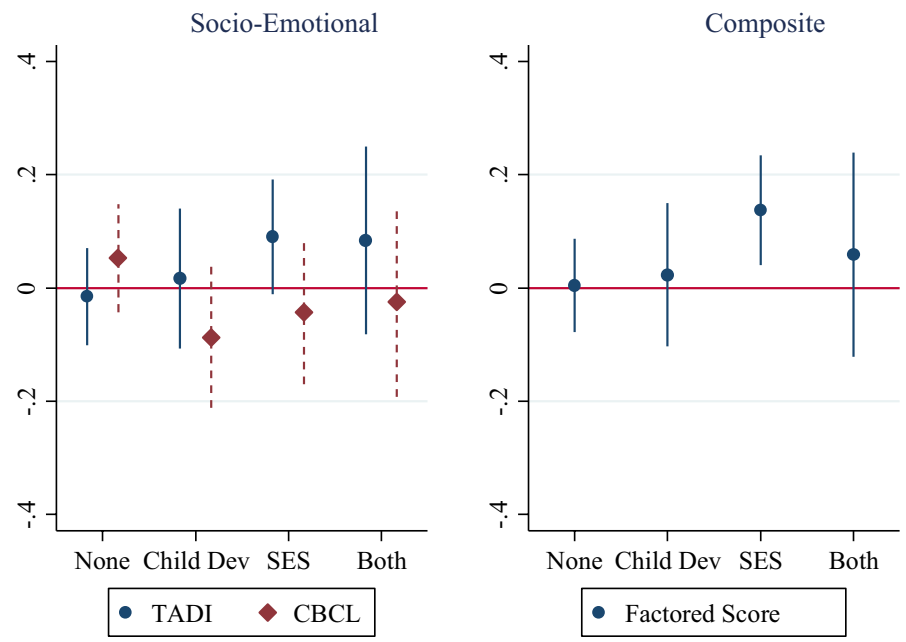

Fig. 3 Improvement in standardized scores by 2010 vulnerability type: Coefficient on natural log of months in center-based care

significant, which may have been due to the smaller sample size of children with both disadvantages.

Results are much weaker when including children who had non-continuous time in care, suggesting consistency in the environment is important (Figure A1). Results were robust to IPW and survey weights (Figure A2). When using a more stringent cut-off of the lowest $6^{\text {th }}$ of the distribution in contrast to the lowest $3^{\text {rd }}$ of the distribution to define child development vulnerability, the results suggested center-based childcare supports equity, since those with both vulnerabilities under this definition benefitted most (Figure A3). 
Improvement in Standardized Scores

By Day Length \& 2010 Vulnerability Type:

Coefficient on Natural Log of Months in Center-Based Care
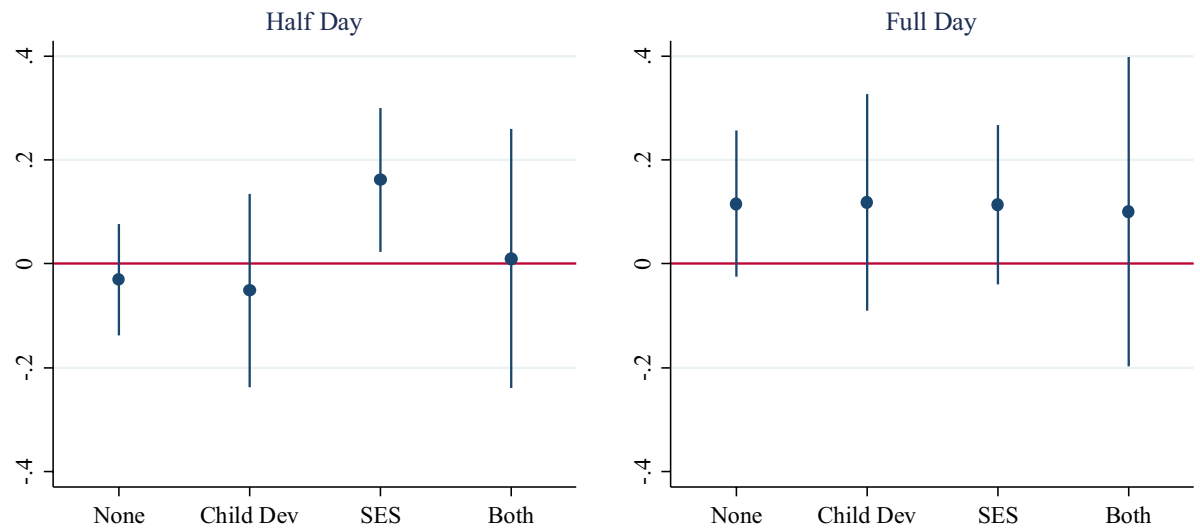

Fig. 4 Improvement in standardized scores by day length \& 2010 vulnerability type: Coefficient on natural $\log$ of months in center-based care

Improvement in Standardized Scores

by Age at Enrollment \& 2010 Vulnerability Type:

Coefficient on Natural Log of Months in Center-Based Care
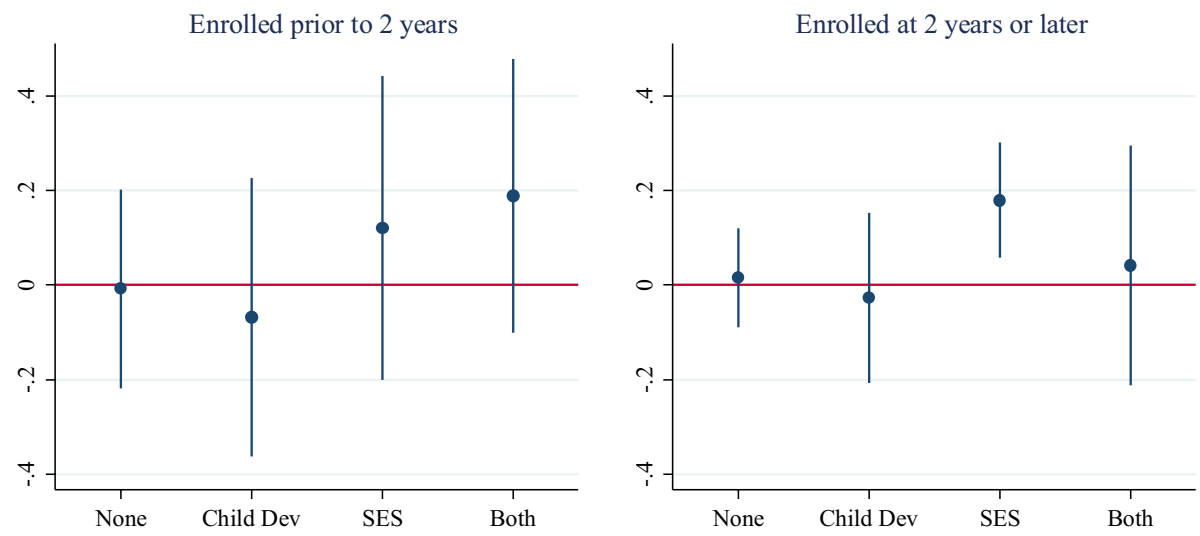

Fig. 5 Improvement in standardized scores by age at enrollment \& 2010 vulnerability type: Coefficient on natural log of months in center-based care

Hypothesis 3 Result: The Full Day Does not Provide Additional Reduction in Inequality I find SES disadvantaged children enrolled in half-day center-based care improve in the composite child development score, which is driven by gains in the cognitive and, to a lesser extent, in the language realm (Fig. 4 \& Supplementary Table A4). A longer period in full-day center-based care is associated with higher outcomes for all groups, but these associations are not statistically significant. 


\section{Hypothesis 4 Result: Among Children Who Enrolled Prior to Age 2 Years, More Time in Center-Based Care Does Not Reduce Inequality I examined the associa-} tions for children who enrolled in center-based child care at age one or earlier and those who enrolled at age two or later (Fig. $5 \&$ Supplementary Table A4). The sample size of the children enrolling at age one year was only 619 children, so statistical power was lower. However, looking at overall patterns, again, the magnitudes of the association between center-based child care and outcomes for children with no disadvantage were small for the children who enrolled at age one year. Associations between length of time in center-based child care and developmental scores among those with the child-development disadvantages tended negative while those among those with both disadvantages tended positive. Results were mixed for those with SES disadvantages, although the (statistically insignificant) coefficient was positive for the composite score. Results for children who entered center-based care at age two years or later echoed the main results; the increase in the composite score was particularly similar for the SES disadvantaged.

\section{Discussion}

Gains in child development associated with more time in center-based care are strongest for children with the SES disadvantage only, with the most robust increase in the language realm. Among this low-SES but not low child development scoring group, results suggest an increase to two years of center-based child care between ages one and three years from of an average of one year may increase child development scores around 0.15 of a standard deviation, controlling for previous child development scores. For those with already low child development scores at age one year, center-based care generally does not associate with child development scores. This suggests that, in Chile, in contrast to a notable United States study (Bitler et al., 2014), center-based care is better at preventing declines in scores rather than helping those in the lower portion of the distribution improve. However, the US evaluation was of a specific program, while the current study includes any type of center-based care. This finding suggests that quality improvements in Chilean center-based care should be aimed toward reducing inequality; efforts to scale up interventions that have proven successful with children in the lower portion of the child development distribution will be the most valuable.

Since these findings suggest increasing center-based care for SES vulnerable children, it is important to examine possible impacts of longer hours of a day in care and earlier enrollment. Though statistically insignificant, more months in full-day center-based care seemed to benefit all groups equally, while more months in center-based care among those attending half-time primarily benefit low-SES children. This suggests that children with lower development scores have more opportunities to improve with a full day in center-based care. Moving enrollment earlier by one year would result in entry into center-based care on average to age one year instead of age two years. Yet the findings regarding age at enrollment indicate few benefits or disadvantages relating to length of time in center-based child care among children who enrolled at age one year or earlier. Results hint at negative associations for those with developmental disadvantage and positive ones for those with SES disadvantage, but these are statistically insignificant. (Associations for those who entered at age two or later mirror the main findings.) These differences may arise due to the smaller portion of the sample that was enrolled at an earlier age or due to selection bias regarding 
when children are enrolled in child care: economically disadvantaged women may need to enter the workforce earlier than wealthier ones.

My results complement the findings of Noboa-Hidalgo and Urzúa's study, which uses a dosage analysis to examine the impacts of early center-based child care for low-income children in Chile. They find center-based child care generally improves child development scores, with their dosage analysis confirming that seven months of care is more beneficial than five months of care. Aligned with these results, the current study confirms benefits of more time in center-based care for low-SES children, particularly in the cognitive realm. However, this finding does not hold for children who have both SES disadvantage and low developmental scores. The omission of a multiple disadvantage analysis may have been limited by Noboa-Hidalgo \& Urzua's sample size, around 500 children. Thus, the current study complements their findings by revealing that the benefits of center-based child care may be limited to the low-SES population.

This study also contrasted SES and child-development disadvantages. It is notable that the intersection of the population with both SES and child-development disadvantages at age one year was not larger given the broad literature indicating that low SES is a predictor of low child development (Walker et al., 2011; Yoshikawa et al., 2012). This finding may be due partially to the nature of the government transfer SUF, which encourages healthy child development through medical check-ups. Additionally, participation in the SUF program corresponds to being a beneficiary of Chile Crece Contigo, Chile's program for strengthening child development for participants in the public health system (around $60 \%$ of the population). Chile's early childhood support programs may already be reducing some of the risk for lower child development at early ages.

This work contributes to research on persistence of the disadvantages. That the SES disadvantage at age one year corresponded to lower scores at age three years indicates that Chile has not been able to completely ameliorate the SES challenges that correspond to lower child development. Likewise, that the children with both SES and child-development disadvantages scored worse than only those with child-development disadvantages also indicates need for intervention among this particularly at-risk group. These findings align with other data from Latin America (including Chile) that indicate SES differences in child development scores in language emerge by age three years (Schady et al., 2015).

I am currently unaware of literature at the population level in Latin America on the persistence of child-development disadvantages beyond those that are established from low SES. My findings suggest that having a child-development disadvantage at age one year corresponds to worsened child development scores at age three. The magnitude of this disadvantage is of similar magnitude as having only an SES disadvantage. Policy to target children in the lower third of the development distribution in Chile may be important in addition to policy targeting low-SES children. For example, the parenting program "Nadie es perfecto" which is offered as a part of Chile Crece Contigo and has shown to have positive impacts on child development, could expand coverage (Bedregal et al., 2013). On the other hand, when controlling for previous child development scores, differences in outcomes between those with the child-development disadvantage and with no disadvantage are small and remain statistically insignificant. In contrast, the differences in outcomes between low-SES children and non-disadvantaged children remain significant even when controlling for previous child development scores. This suggests that, while low, scores are not worsening for children with the child-development disadvantage only, unlike for the children with the SES disadvantages. Future research will need to examine if these differences persist later in life. 
Interestingly, children with both disadvantages, once controlling for age one-year ability, do not perform as poorly as children with the SES disadvantage only. Perhaps some of these children have been earlier identified as needing help since they are beneficiaries of the social services sector. This finding suggests that those most at risk for the largest decline in age-standardized scores are children with low SES but are of average levels of child development. This conclusion could partially be an artifact of the data, however, since these are relative scores.

This study has a number of strengths. Using a large sample of children, I examine participation in centers during ages one to three years, younger ages than those primarily explored in much of the literature on center-based care and early child development. The retrospective data on child-care history is thorough, and includes all center-based care types; the focus is not on a particular program. Though this study has some limitations such as non-random assignment, the longitudinal analysis controlling for baseline child development allows for a value-added interpretation (Todd \& Wolpin, 2003). I also limited the sample to center-based-care participants in order to limit selection bias. I am unable to take quality into account, since parental measures of quality lacked variance (most thought highly of their child's care center) but data suggest that increase in services has not resulted in overcrowding (Reyes \& Urzúa, 2013).

One limitation is particular to some dosage analyses. Age at enrollment, length of time in care, and quality may all be confounded. A longer time in care occurs simultaneously with earlier enrollment. Additionally, child care quality may influence when mothers decide to enroll their children. If the quality of care is low, mothers may wait until children are older to enroll them. Unlike studies with child care of consistent high quality (Zambrana et al., 2016) or studies that can control for quality through direct observation (McCartney et al., 2010), the ELPI data does not have information on child care quality, only perception of child care quality, which was almost uniformly high.

Future research on the prevalence and persistence of child-development disadvantages in Chile can consider populations beyond children who attend center-based care and examine the effectiveness of alternative interventions, such as parenting programs to encourage child stimulation. Additionally, different structures in center design can be contrasted to determine which aspects of the centers are contributing to children's advancements. Current research suggests that improving teacher training in Chile can improve the quality of preschool classroom experiences, but has not yet translated into improved child outcomes (Yoshikawa et al., 2015). Moving forward, refining programs to better serve those who have developmental disadvantages in addition to heightened concern for low-SES children should help improve Chilean children's advancement.

Supplementary Information The online version contains supplementary material available at https://doi. org/10.1007/s10566-021-09634-0.

Acknowledgements I thank Lia Fernald and Jere Behrman for their supportive mentorship and valuable suggestions. This work was funded by Eunice Kennedy Shriver National Institute of Child Health and Human Development grants K99HD088751, R01HD065436, and Grand Challenges Canada Grant 0072-03.

Open Access This article is licensed under a Creative Commons Attribution 4.0 International License, which permits use, sharing, adaptation, distribution and reproduction in any medium or format, as long as you give appropriate credit to the original author(s) and the source, provide a link to the Creative Commons licence, and indicate if changes were made. The images or other third party material in this article are included in the article's Creative Commons licence, unless indicated otherwise in a credit line to the material. If material is not included in the article's Creative Commons licence and your intended use is not permitted by statutory regulation or exceeds the permitted use, you will need to obtain permission directly from the copyright holder. To view a copy of this licence, visit http://creativecommons.org/licenses/by/4.0/. 


\section{References}

Abufhele, A., Contreras, D., Puentes, E., \& Telias, A. (2020). Socioeconomic gradients in child development: Evidence from a Chilean longitudinal study 2010-2017 (No. 509; Serie de Documentos de Trabajo). Facultad de Economia y Negocios, Universidad de Chile.

Achenbach, T. M., \& Rescorla, L. A. (2000). Manual for the ASEBA preschool forms \& profiles. University of Vermont, Research Center for Children, Youth \& Families.

Aguilera, X., Gonzalez, C., Guerrero, A., Hoffeister, L., Cardenas, P., Burgos, A., Medina, B., \& Vallebuona, C. (2006). II Encuesta de Calidad de Vida y Salud Chile 2006: Informe de Resultados Total Nacional. Ministerio de Salud. http://www.crececontigo.gob.cl/wp-content/uploads/2015/11/ENCAVI2006.pdf.

Amior, M., Carneiro, P., Galasso, E., \& Ginja, R. (2012). Overcoming barriers to the take-up of social subsidies. IZA/World Bank.

Anderson, L. M., Shinn, C., Fullilove, M. T., Scrimshaw, S. C., Fielding, J. E., Normand, J., \& CarandeKulis, V. G. (2003). The effectiveness of early childhood development programs: A systematic review. American Journal of Preventive Medicine, 24(3), 32-46. https://doi.org/10.1016/S0749-3797(02) 00655-4

Ansari, A., \& Winsler, A. (2012). School readiness among low-income, Latino children attending family childcare versus centre-based care. Early Child Development and Care, 182(11), 1465-1485.

Atalah, S. E., Cordero, V. M., Guerra, Z. M. E., Quezada, L. S., Carrasco, F. X., \& Romo, M. M. (2014). Monitoreo de los indicadores del Programa "Chile Crece Contigo" 2008-2011. Revista Chilena De Pediatría, 85(5), 569-577. https://doi.org/10.4067/S0370-41062014000500007

Averdijk, M., Besemer, S., Eisner, M., Bijleveld, C., \& Ribeaud, D. (2011). The relationship between quantity, type, and timing of external childcare and child problem behaviour in Switzerland. European Journal of Developmental Psychology, 8(6), 637-660.

Bassok, D., Fitzpatrick, M., Greenberg, E., \& Loeb, S. (2016). Within-and between-sector quality differences in early childhood education and care. Child Development, 87(5), 1627-1645.

Bedregal, P., Carneiro, P., Cordero, M., Galasso, E., \& López, I. (2013). Evaluación de Impacto del programa "Nadie es Perfecto". Resultados Pre-Tratamiento. Informe al Ministerio de Salud de Chile.

Behrman, J., Bravo, D., \& Urzua, S. (2010). Encuesta Longitudinal de la Primera Infancia: Aspectos Metodologicos y Primeros Resultados. Universidad de Chile. http://www.crececontigo.gob.cl/wpcontent/uploads/2015/12/INforme-ELPI-2010.pdf.

Behrman, J. R., Cheng, Y., \& Todd, P. E. (2004). Evaluating preschool programs when length of exposure to the program varies: A nonparametric approach. Review of Economics and Statistics, 86(1), 108-132. https://doi.org/10.1162/003465304323023714

Behrman, J., Contreras, D., Palma, I., \& Puentes, E. (2017). Wealth disparities for early childhood anthropometrics and skills: Evidence from Chilean longitudinal data (No. 17-019; PIER Working Paper). Penn Institute for Economic Research. https://www.ssrn.com/abstract=3044485.

Belsky, J., Vandell, D. L., Burchinal, M., Clarke-Stewart, K. A., McCartney, K., \& Owen, M. T. (2007). Are there long-term effects of early child care? Child Development, 78(2), 681-701. https://doi.org/10. 1111/j.1467-8624.2007.01021.x

Berlinski, S., Galiani, S., \& Manacorda, M. (2008). Giving children a better start: Preschool attendance and school-age profiles. Journal of Public Economics, 92(5), 1416-1440. https://doi.org/10.1016/j.jpube co.2007.10.007

Bernal, R., \& Fernández, C. (2013). Subsidized childcare and child development in Colombia: Effects of Hogares Comunitarios de Bienestar as a function of timing and length of exposure. Social Science \& Medicine, 97, 241-249. https://doi.org/10.1016/j.socscimed.2012.10.029

Berry, D., Blair, C., \& Granger, D. A. (2016). Child care and cortisol across infancy and toddlerhood: Poverty, peers, and developmental timing. Family Relations, 65(1), 51-72. https://doi.org/10.1111/fare. 12184

Bitler, M., Hoynes, H., \& Domina, T. (2014). Experimental evidence on distributional effects of head start (NBER Working Paper No. 20434). National Bureau of Economic Research, Inc. https://econpapers. repec.org/paper/nbrnberwo/20434.htm.

Bronfenbrenner, U., \& Morris, P. A. (1998). The ecology of developmental processes. In Handbook of child psychology: Vol. 1. Theoretical models of human development (pp. 993-1028). Wiley. http://psycnet. apa.org/psycinfo/2005-01926-019.

Camilli, G., Vargas, S., Ryan, S., \& Barnett, W. S. (2010). Meta-analysis of the effects of early education interventions on cognitive and social development. Teachers College Record, 112(3), 579-620.

Centro de Estudios MINEDUC. (2013). Imacto de asistir a Educacion Parvularia. Ministerio de Educacion. 
Cortázar, A. (2015). Long-term effects of public early childhood education on academic achievement in Chile. Early Childhood Research Quarterly, 32, 13-22. https://doi.org/10.1016/j.ecresq.2015.01.003

Côté, S. M., Doyle, O., Petitclerc, A., \& Timmins, L. (2013). Child care in infancy and cognitive performance until middle childhood in the millennium cohort study. Child Development, 84(4), 1191-1208. https://doi.org/10.1111/cdev.12049

Crookston, B. T., Dearden, K. A., Alder, S. C., Porucznik, C. A., Stanford, J. B., Merrill, R. M., Dickerson, T. T., \& Penny, M. E. (2011). Impact of early and concurrent stunting on cognition. Maternal \& Child Nutrition, 7(4), 397-409. https://doi.org/10.1111/j.1740-8709.2010.00255.x

Cunha, F., \& Heckman, J. (2007). The technology of skill formation. The American Economic Review, 97(2), 31-47.

De la Cruz, M. V., \& González, M. (1998). Inventario de Desarrollo Battelle. Madrid: Tea Ediciones.

Del Boca, D., Piazzalunga, D., \& Pronzato, C. (2018). The role of grandparenting in early childcare and child outcomes. Review of Economics of the Household, 16(2), 477-512. https://doi.org/10.1007/ s11150-017-9379-8

Doyle, O., Harmon, C. P., Heckman, J. J., \& Tremblay, R. E. (2009). Investing in early human development: Timing and economic efficiency. Economics \& Human Biology, 7(1), 1-6. https://doi.org/10. 1016/j.ehb.2009.01.002

Duncan, G. J., Dowsett, C. J., Claessens, A., Magnuson, K., Huston, A. C., Klebanov, P., Pagani, L. S., Feinstein, L., Engel, M., \& Brooks-Gunn, J. (2007). School readiness and later achievement. Developmental Psychology, 43(6), 1428-1446. https://doi.org/10.1037/0012-1649.43.6.1428

Dunn, L. M., \& Dunn, L. M. (1997). PPVT-III: Peabody picture vocabulary test. American Guidance Service Circle Pines, MN.

Erikson, E. H. (1950). Childhood and society (1st ed.). Norton.

Evans, G. W., Li, D., \& Whipple, S. S. (2013). Cumulative risk and child development. Psychological Bulletin, 139(6), 1342-1396. https://doi.org/10.1037/a0031808

Farkas, C., Vallotton, C. D., Strasser, K., Santelices, M. P., \& Himmel, E. (2017). Socioemotional skills between 12 and 30 months of age on Chilean children: When do the competences of adults matter? Infant Behavior and Development, 49, 192-203. https://doi.org/10.1016/j.infbeh.2017.09.010

Fernald, A., Marchman, V. A., \& Weisleder, A. (2013). SES differences in language processing skill and vocabulary are evident at 18 months. Developmental Science, 16(2), 234-248. https://doi.org/10. 1111/desc. 12019

Fernald, L. C. H., Kariger, P., Hidrobo, M., \& Gertler, P. J. (2012). Socioeconomic gradients in child development in very young children: Evidence from India, Indonesia, Peru, and Senegal. Proceedings of the National Academy of Sciences of the United States of America, 109(Suppl 2), 1727317280. https://doi.org/10.1073/pnas.1121241109

Fernald, L. C. H., Weber, A., Galasso, E., \& Ratsifandrihamanana, L. (2011). Socioeconomic gradients and child development in a very low income population: Evidence from Madagascar. Developmental Science, 14(4), 832-847. https://doi.org/10.1111/j.1467-7687.2010.01032.x

Geoffroy, M.-C., Côté, S. M., Giguère, C. -É., Dionne, G., Zelazo, P. D., Tremblay, R. E., Boivin, M., \& Séguin, J. R. (2010). Closing the gap in academic readiness and achievement: The role of early childcare. Journal of Child Psychology and Psychiatry, 51(12), 1359-1367. https://doi.org/10. 1111/j.1469-7610.2010.02316.x

Gerard, J. M., \& Buehler, C. (2004). Cumulative environmental risk and youth maladjustment: The role of youth attributes. Child Development, 75(6), 1832-1849. https://doi.org/10.1111/j.1467-8624. 2004.00820.x

Gertler, P., Heckman, J., Pinto, R., Zanolini, A., Vermeersch, C., Walker, S., Chang, S. M., \& Grantham-McGregor, S. (2014). Labor market returns to an early childhood stimulation intervention in Jamaica. Science (New York, N.Y.), 344(6187), 998-1001. https://doi.org/10.1126/science.1251178

Glascoe, F. P., \& Byrne, K. E. (1993). The usefulness of the Battelle developmental inventory screening test. Clinical Pediatrics, 32(5), 273-280. https://doi.org/10.1177/000992289303200504

Hansen, K., \& Hawkes, D. (2009). Early childcare and child development. Journal of Social Policy, 38(2), 211-239. https://doi.org/10.1017/S004727940800281X

Havnes, T., \& Mogstad, M. (2011). No child left behind: Subsidized child care and children's long-run outcomes. American Economic Journal: Economic Policy, 3(2), 97-129. https://doi.org/10.1257/ pol.3.2.97

Janta, B. (2014). Caring for children in Europe. https://www.rand.org/pubs/research_reports/RR554. html.

Kuehnle, D., \& Oberfichtner, M. (2020). Does starting universal childcare earlier influence children's skill development? Demography. https://doi.org/10.1007/s13524-019-00836-9 
Lee, V. E., \& Burkam, D. T. (2002). Inequality at the starting gate: Social background differences in achievement as children begin school. Economic Policy Institute Washington, DC. http://epsl.asu. edu/epru/articles/EPRU-0603-138-OWI.pdf.

McCartney, K., Burchinal, M., Clarke-Stewart, A., Bub, K. L., Owen, M. T., \& Belsky, J. (2010). Testing a series of causal propositions relating time in child care to children's externalizing behavior. Developmental Psychology, 46(1), 1.

Ministerio de Desarrollo Social. (2019). Encuesta Longitudianal de la Primera Infancia. http://obser vatorio.ministeriodesarrollosocial.gob.cl/elpi/elpi_bd.php.

Narea, M., Arriagada, V., \& Allel, K. (2020a). Center-based care in toddlerhood and child cognitive outcomes in Chile: The moderating role of family socio-economic status. Early Education and Development, 31(2), 218-233. https://doi.org/10.1080/10409289.2019.1626191

Narea, M., Toppelberg, C. O., Irarrázaval, M., \& Xu, J. (2020b). Maternal and non-maternal care in infancy and later child cognitive, language and motor development in Chile: Does type of care matter? Early Childhood Research Quarterly, 51, 204-214. https://doi.org/10.1016/j.ecresq.2019.10. 010

Newborg, J., Stock, J. R., \& Wnek, L. (1996). Battelle: Inventario de desarrollo. TEA.

Noboa-Hidalgo, G. E., \& Urzúa, S. S. (2012). The effects of participation in public child care centers: Evidence from Chile. Journal of Human Capital, 6(1), 1-34. https://doi.org/10.1086/664790

Nores, M., Bernal, R., \& Barnett, W. S. (2019). Center-based care for infants and toddlers: The aeioTU randomized trial. Economics of Education Review, 72, 30-43. https://doi.org/10.1016/j.econedurev. 2019.05.004

OECD - Social Policy Division. (2016). LMF1.2: Maternal employment rates. Directorate of Employment, Labour and Social Affairs. https://www.oecd.org/els/family/LMF_1_2_Maternal_Employment.pdf.

Pardo, M., Gomez, M., \& Edwards, M. (2012). Test de Aprendizaje y Desarrollo Infantil (TADI): UNICEF, 14 . http://unicef.cl/web/test-de-aprendizaje-y-desarrollo-infan til-tadi-para-ninos-y-ninas-de-3-meses-a-6-anos/.

Paxson, C., \& Schady, N. (2007). Cognitive development among young children in Ecuador: The roles of wealth, health, and parenting. The Journal of Human Resources, 42(1), 49-84. https://doi.org/10. 3368/jhr.XLII.1.49

Reveco, O., \& Mella, O. (1999). Impacto de la educación parvularia en la educación básica. Manuscript. http://sites.google.com/site/camoc33/impacto.doc.

Reyes, L., \& Urzua, S. (2012). La demanda y oferta de educación temprana en Chile. Estudios Públicos, $126,45-86$.

Reyes, L., \& Urzúa, S. S. (2013). Demand and supply of early education in Chile. Centro de Estudios Publicos. http://www.cepchile.c1/2_5046/doc/demand_and_supply_of_early_education_in_chile. html\#.Uxj0O4UmzHp.

Rubio-Codina, M., Attanasio, O., Meghir, C., Varela, N., \& Grantham-McGregor, S. (2015). The socioeconomic gradient of child development: Cross-sectional evidence from children 6-42 months in Bogota. Journal of Human Resources, 50(2), 464-483. https://doi.org/10.3368/jhr.50.2.464

Schady, N., Behrman, J., Araujo, M. C., Azuero, R., Bernal, R., Bravo, D., Lopez-Boo, F., Macours, K., Marshall, D., Paxson, C., et al. (2015). Wealth gradients in early childhood cognitive development in five Latin American countries. Journal of Human Resources, 50(2), 446-463. https://doi.org/10. 3368/jhr.50.2.446

Seguel, X., Edwards, M., Hurtado, M., Bañados, J., Covarrubias, M., Wormald, A., de Amesti, A., Chadwick, M., Galaz, H., \& Sánchez, A. (2012). ¿Qué Efecto Tiene Asistir a Sala Cuna y Jardín Infantil Desde los Tres Meses Hasta los Cuatro Años de Edad?: Estudio Longitudinal en la Junta Nacional de Jardines Infantiles. Psykhe (santiago), 21(2), 87-104.

Sylva, K., Ereky-Stevens, K., \& Aricescu, A. M. (2015). Curriculum quality analysis and impact review of European early childhood education and care (ECEC). Early childhood education and care: Promoting quality for individual, social and economic benefits. D, 2 .

The World Bank. (2017). Labor force participation rate, female (\% of female population ages 15+). Data: World Development Indicators. http://data.worldbank.org/indicator/SL.TLF.CACT.FE.ZS/.

Todd, P. E., \& Wolpin, K. I. (2003). On the specification and estimation of the production function for cognitive achievement. The Economic Journal, 113(485), F3-F33. https://doi.org/10.1111/14680297.00097

United States Department of Labor. (2016). Labor force participation rate of mothers and fathers by marital status and age of youngest child. https://www.dol.gov/wb/stats/NEWSTATS/latest/Lf_par_ rate_mothers_father_marital_age_uchild_hisp2016_txt.htm. 
Vandell, D. L., Burchinal, M., \& Pierce, K. M. (2016). Early child care and adolescent functioning at the end of high school: Results from the NICHD study of early child care and youth development. Developmental Psychology, 52(10), 1634-1645. https://doi.org/10.1037/dev0000169

Von Stumm, S., \& Plomin, R. (2015). Socioeconomic status and the growth of intelligence from infancy through adolescence. Intelligence, 48, 30-36. https://doi.org/10.1016/j.intell.2014.10.002

Vygotskiur, L. S. (1978). Mind in society: The development of higher psychologicalprocesses (M. Cole, Ed.). Harvard University Press.

Waldfogel, J., \& Washbrook, E. (2011). Early years policy [Research article]. Child Development Research. https://doi.org/10.1155/2011/343016

Walker, S. P., Wachs, T. D., Grantham-McGregor, S., Black, M. M., Nelson, C. A., Huffman, S. L., Baker-Henningham, H., Chang, S. M., Hamadani, J. D., Lozoff, B., et al. (2011). Inequality in early childhood: Risk and protective factors for early child development. The Lancet, 378(9799), 13251338. https://doi.org/10.1016/S0140-6736(11)60555-2

Yoshikawa, H., Aber, J. L., \& Beardslee, W. R. (2012). The effects of poverty on the mental, emotional, and behavioral health of children and youth: Implications for prevention. American Psychologist, 67(4), 272-284. https://doi.org/10.1037/a0028015

Yoshikawa, H., Leyva, D., Snow, C. E., Treviño, E., Barata, M., Weiland, C., Gomez, C. J., Moreno, L., Rolla, A., \& D'Sa, N. (2015). Experimental impacts of a teacher professional development program in Chile on preschool classroom quality and child outcomes. Developmental Psychology, 51(3), 309. https://doi.org/10.1037/a0038785

Zafe Contreras, F. (Ed.). (2013). Informe de fiscalizacion 2012. JUNJI Ministerio de Educacion.

Zambrana, I. M., Dearing, E., Nærde, A., \& Zachrisson, H. D. (2016). Time in early childhood education and care and language competence in Norwegian four-year-old girls and boys. European Early Childhood Education Research Journal, 24(6), 793-806. https://doi.org/10.1080/1350293X.2015.1035538

Zigler, E., Gilliam, W. S., \& Jones, S. M. (2006). A vision for universal preschool education. Cambridge University Press.

Publisher's Note Springer Nature remains neutral with regard to jurisdictional claims in published maps and institutional affiliations. 